\title{
Advancing Surveillance Outside the USA: The Canadian Policy, Practice, and Research Context
}

\author{
Effie Gournis ${ }^{\star 1,2}$ and David Buckeridge $\mathrm{e}^{3,4}$ \\ ${ }^{1}$ Toronto Public Health, Toronto, ON, Canada; ${ }^{2}$ Dalla Lana School of Public Health - University of Toronto, Toronto, ON, Canada; \\ ${ }^{3}$ McGill University, Montreal, QC, Canada; ${ }^{4}$ Direction de Sante Publique de Montreal, Montreal, QC, Canada
}

\section{Objective}

1) To explore how ISDS can better support researchers and public health practitioners working in the field of disease surveillance outside the United States; and

2) To identify current surveillance issues in the Canadian public health system where ISDS can support dialogue and action.

\section{Introduction}

The international Society for Disease Surveillance has successfully brought together practitioners and researchers to share tools, ideas, and strategies to strengthen health surveillance systems. The Society has evolved from an initial focus on syndromic surveillance to a broader consideration of innovation in health surveillance. More recently, ISDS has also worked to support surveillance research and practice in International resource-constrained settings. Individuals who work in surveillance in developed countries outside the USA, however, have received little direct attention from ISDS. The policy and practice contexts in these countries are often quite different than the USA, so there is a need to support surveillance innovation in these countries in a manner that fits the context. Canadian surveillance practitioners and researchers comprise the largest International group of ISDS members, and these members have expressed an interest in working with ISDS to translate surveillance innovations into practice in Canada, where a national surveillance network and forum is lacking. This Round Table will consider how ISDS can help to support members in countries like Canada and will identify next steps for promoting the science and practice of disease surveillance in the Canadian context.

\section{Methods}

Individuals attending the ISDS 2012 Conference with an interest in public health surveillance in Canada or other similar countries outside the USA will be invited to discuss how ISDS can better support their activities. The discussion will be structured around questions and results received for a survey circulated to Canadian ISDS members. The goal will be to discuss whether there is a specific formal role ISDS can play in helping members in Canada and other similar countries working in public health surveillance.

\section{Results}

Discussion will be prompted through sharing results of a recent survey distributed to all Canadian ISDS members and affiliates aimed at gauging their interest in developing a Canadian focused group within ISDS, whether they believe there is a need, and how we might accomplish this. The survey questions, range of answers, and implications to future actions suggested in survey responses would drive the discussion.

\section{Keywords}

International surveillance; Canada; Surveillance network

\section{*Effie Gournis}

E-mail: egourni@toronto.ca 